\title{
Epigenetic signals of how social disadvantage "gets under the skin": a challenge to the public health community
}

\author{
"As environmental epigenetics studies continue to indicate \\ the specific exposures that have clinically significant \\ ramifications for women and their offspring ... then a \\ concerted, coordinated effort ought to be made .... so that \\ we can more fully understand the health implications of \\ these exposures within the context of multiple biological \\ pathways and clinical end points."
}

First draft submitted: 13 January 2017; Accepted for publication: 20 January 2017; Published online: 22 February 2017

Keywords: cohort studies $\bullet$ disparities $\bullet$ epigenetics $\bullet$ HPA axis $\bullet$ maternal health

- methylation $\bullet$ psychosocial stress $\bullet$ resilience

"Modern science must go beyond merely expressing intellectual ideas to be an application to 'work that sustains life'."

"With this emphasis we declare a commitment to social research practice that is sustained... by a moral concern to be actively involved in the creation of humane forms of society" [1].

- Wilkinson and Kleinman (2016)

For decades, feminists criticized public health programs aimed at improving birth outcomes by providing healthcare and other services to women only during pregnancy. They knew what recent environmental epigenetics research is now confirming: that the health of children is inextricably linked to the health of women, whether pregnant or not. A growing body of epigenetics research is revealing just how critical a mother's experience is in shaping the epigenome and future health trajectory of her infant. A cascade of complex biological events occur in the in utero environment that can influence an individual's health well into adulthood $[2,3]$. Epigenetic alterations in the prenatal period have been associated with a multitude of fetal outcomes [4-7]. These changes have been hypothesized to be the functional molecular basis of altered developmental programming, which in turn induces (mal)adaptive changes that influence disease risk in adulthood [8]. The hypothalamic-pituitary-adrenal (HPA) axis seems to be especially susceptible to such perinatal programming, and there is a rich epigenetics literature documenting associations between maternal psychosocial stressors and infant DNA methylation of HPA axisrelated genes, as well as associations between such methylation in infants and diverse fetal outcomes [9].

Adverse maternal mental health (i.e., depression, anxiety during pregnancy and war-related trauma) has been consistently associated with increased neonatal $N R 3 C 1$ and HSD11ß2 methylation [4,6-7,10-11]. Higher maternal BMI and waist circumference has also been associated with increased neonatal NRC31 and HSD11ß2 methylation [5]. Maternal exposures experienced long before pregnancy also seem to shape an infant's health. Recent research has shown, for example, that

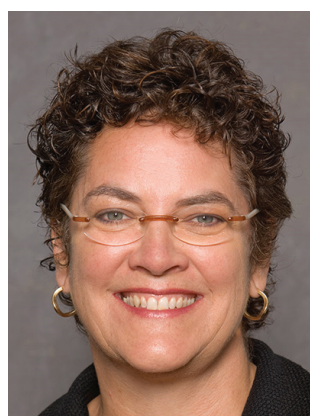

Alexandra E Shields Harvard/MGH Center on Genomics, Vulnerable Populations \& Health Disparities, Department of Medicine Massachusetts General Hospital, 50 Staniford St, Suite 901, Boston, MA 02114, USA

and

Department of Medicine, Harvard Medical School, 25 Shattuck St, Boston, MA 02115, USA

and

National Consortium on Psychosocial Stress, Spirituality \& Health, Massachusetts General Hospital, 50 Staniford St, Suite 901, Boston, MA 02114, USA

and

Broad Institute of MIT \& Harvard, 415 Main Street, Cambridge, MA 02142, USA

ashields1@partners.org

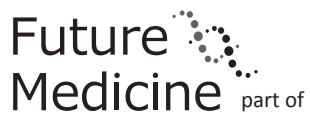
fsg 
chronic interpersonal trauma experienced by mothers throughout their lives up until pregnancy is significantly associated with increased IgE antibody levels in cord blood of their children at birth [12]. Low socioeconomic status experienced by mothers during their childhood is also associated with increased cord blood $\operatorname{IgE}$ levels in their children [13]. Maternal exposure to stressful life events prior to conception has also been associated with increased risk of very low birth weight $(<1500 \mathrm{~g})$ for their infants and has been shown to predict poor infant health at both 9 and 24 months of age [14]. A comprehensive review of such research by Bowers and Yehuda can be found in Neuropsychopharmacology [15].

"By shedding light on the biological pathways through which such exposures are translated into concrete, measurable increased risk of various diseases, epigenetics research provides a useful tool for refocusing policy makers' attention back to the communities in which people live and work, and the daily quality of their lives that shape their health and those of their offspring."

Lastly, although this is a contested field, there is also recent evidence that maternal stressors and trauma experienced before pregnancy might leave DNA methylation signatures in a woman's epigenome that are then passed on to her children. Just in the past year, Yehuda et al. demonstrated an association between preconception maternal trauma and changes in maternal DNA methylation that was correlated for the first time with methylation levels in affected women's children at the same genomic site (in this case, changes on the same site in a functional intronic region of the FKBP5 gene) [16]. Such methylation is likely to be functionally significant, as it was also associated with salivary cortisol levels among children in this study. Further, a recent article by Sen et al. demonstrated that DNA methylation associated with lead exposure in mothers was correlated with the same methylation status in both their children and grandchildren, which is the first empirical evidence of multigenerational epigenetic inheritance [17]. An article recently published in Cell corroborates the biological plausibility of the inter-generational epigenetic transmission documented in these studies, showing for the first time that despite the genome-wide DNA demethylation that occurs in human primordial germ cells, methylation can persists at specific loci throughout the genome [18].

\section{What epigenetics adds to our understanding of health disparities}

It is important to note that differential DNA methylation levels induced by environmental and psychosocial stressors may have important health implications [19].
Indeed, recent research has thus far linked differential DNA methylation of genes in the stress pathway to increased risk of breast cancer [20], small-cell lung cancer [21], borderline personality disorder [22], depression [23-25], Alzheimer's [26], post traumatic stress disorder [27-31], chronic kidney disease [32] and hypertension [33]. Environmental epigenetics might therefore be one of our most successful methods for exploring the mechanistic pathways through which psychosocial, environmental or other stressors operate to dysregulate the body's regulatory mechanisms to increase risk of disease.

As such, environmental epigenetics also provides a compelling body of evidence to help understand the underlying causal pathways that lead to disparities in the burden of disease. How does social disadvantage - being in a group that experiences disproportionate exposures to social and environmental stressors - get 'under the skin', so to speak, and result in higher rates of hypertension or cancer? Poor women suffer a disproportionate burden of psychosocial stressors, including poverty, abuse, victimization and other forms of stress. Poor women are also at increased risk of exposure to air pollution and other environmental toxins [34,35]. Because of racism, residential segregation, and structural inequality in our society, minority women are disproportionately represented among lowincome women and are disproportionately exposed to poor environments. To the extent that epigenetics offers a view to understand the pathways through which a mother's social disadvantage in the form of abuse, interpersonal violence, or even exposure to pollution $[36,37]$ could be translated to her child's vulnerability to disease, this new knowledge may galvanize support for public health interventions and generate new ideas for effective interventions. We have always known that poverty, child abuse, trauma, air pollution, and other adverse exposures were bad for people's health. By shedding light on the biological pathways through which such exposures are translated into concrete, measurable increased risk of various diseases, epigenetics research provides a useful tool for refocusing policy makers' attention back to the communities in which people live and work, and the daily quality of their lives that shape their health and those of their offspring. Epigenetics offers some high priority targets for public health interventions, as well as novel metrics (i.e., demethylation of target loci) with which to measure their effectiveness, that could be leveraged to reduce disparities in the burden of chronic illness.

\section{Using epigenetics research to prioritize data collection across national cohort studies}

As epigenetics research continues to generate a growing list of various psychosocial, social and environmental 
exposures linked to increased risk of numerous chronic diseases, not only demonstrating an association, but shedding light on the biological pathway though which such exposures are translated into increased risk of disease, it makes sense to prioritize tracking such exposures in national data collection efforts used to understand disease risk over time. Optimally evaluating the relative contribution of various social and environmental assaults that contribute to vulnerability to disease in a robust, systematic way will require marshaling the resources of prospective cohort studies, which represent a treasure trove of high quality data on individuals, often collected every other year, and often including a wealth of genetic data, biomarkers and clinical exam data, along with rich self-reported survey data. To date, there has been no national, systematic effort in the US to galvanize the epidemiological community to empirically evaluate various measures of social, psychosocial and environmental measures; prioritize which measures are most important for all cohorts to collect within each domain; and implement core common measure sets within each domain across all cohorts. While there have been efforts to create measure recommendations or resources in the form of various toolkits, such as the PhenX toolkit, these efforts are altogether different from what I'm proposing. The PhenX measures, for example, represent different content areas where a set of measures were identified by a group of experts; the process was not data driven or evidence-based. What I suggest is a much more rigorous, empirically-driven process of measure selection based on which measures are proven to have the most biological resonance (i.e., a demonstrated impact on clinically-relevant biological mechanisms) in high-quality, prospective analyses, replicated in at least one or two additional studies. Cohort study Principle Investigators must be able to review the evidence for specific measures and reach consensus on a core set of measures in key domains based on such high-quality evidence.

As environmental epigenetics studies continue to indicate the specific exposures that have clinically significant ramifications for women and their offspring, and once these results are replicated, then a concerted, coordinated effort ought to be made to include and measure these exposures across as many cohort studies as possible so that we can more fully understand the health implications of these exposures within the context of multiple biological pathways and clinical end points. Ideally, information about the social and environmental influences on individuals' health would also be collected during clinical visits and entered into their electronic health record, which would allow for much more detailed data to be analyzed later in tandem with epidemiological data. It should be noted that the types of data collected in cohort studies, and the range of exposures that these data can address, can never fully capture the full range of social, environmental and behavioral factors that shape a person's life. Nor would any survey researcher or epidemiologist suggest that it could. As our anthropologist colleagues have pointed out $[38,39]$, survey-based measures or other exposure data used in epigenetics research can never capture the richness of human experience in the way that an indepth qualitative or ethnographic investigation can. The practical challenge, nonetheless, is to work within these constraints to most effectively capture the impact of specific exposures in a parsimonious way to facilitate analyses across hundreds of thousands of individuals in order to advance knowledge and inform public policy. As different measures are evaluated, exposures that have high health impact and disproportionately affect poor communities should be high priority for data collection in the public health and healthcare sectors based on the potential to improve population health, reduce health disparities - a national priority in the US [40] - and the principle of justice. As Powers and Faden argue in their book, Social Justice: The Moral Foundations of Public Health and Health Policy, those who have experienced systematic disadvantage deserve special consideration in the allocation of public resources [41].

\section{"With respect to disparities, emerging epigenetics research suggests that supporting the material and psychosocial health of poor and minority women throughout the lifecourse should be a cornerstone of any long-term strategy to not only address perinatal and infant health, but to eliminate health disparities in the general population."}

If cohorts can agree on common measure adoption, this common data across cohorts would support a whole new generation of analyses focused not only on identifying factors associated with disease risk, but on more fully understanding the mechanistic pathways through which various exposures operate to affect the etiology of disease and health disparities in our nation. Once such a coordinated, common measure infrastructure was in place, the community of prospective cohort studies would be positioned to make a unique contribution to understanding the etiology of disease and to generating data to help guide efforts to reduce health disparities. They would be adequately powered to answer key empirical questions, and provide unmatched empirical data to help policy makers seeking to identify the optimal allocation of public health resources to interventions targeting various points along the life course trajectory. 
As priorities areas are identified for common measure development, a process for empirically assessing the optimal way to measure each exposure should be conducted, and then consensus reached among cohort leaders regarding the common measure to be adopted for each high priority exposure. While much recent work has focused on psychosocial exposures, exposures to environmental toxins are equally important. Recent work has suggested, for example, that air pollution is also associated with differential DNA methylation, histone modifications and expression of noncoding RNAs [36], which may in turn also be associated with preterm birth [36,37]. Behavioral measures must also be taken into consideration. Further, given the evidence thus far regarding the biological impact of social disadvantage, other potential measures that make sense theoretically but have not yet been assessed should also be considered for empirical assessment. Such investigations would then feed into decisions regarding priorities for national measure harmonization and data collection.

\section{Investigating sources of resiliency}

In reflecting on the potential contribution of environmental epigenetics research to population health, it is important to note that nearly all extant epigenetics studies focus on adverse exposures. Little research to date has focused on positive mediating influences such as social support, coping and spirituality that might offset the adverse effects of stress or adverse life circumstances and promote resiliency and health. Focusing on positive mediating influences has the benefit of often being more tractable and amenable to intervention than adverse influences, such as psychosocial stress at the individual or community level. Serious studies of spirituality and religious coping [42] have perhaps been hampered by the unfortunate intersections between religion and public health to date, but this is unfortunate since some of the most systematically disadvantaged communities in American society - AfricanAmerican and Hispanic/Latino communities - are also the nation's most religious communities [43]. Thus, an important opportunity to explore new avenues for creative, effective interventions is likely being missed. A growing body of high quality studies have linked religious coping [44-51] and mind-body practices [52-59] , for example, with improved health outcomes. Further research is needed to understand the ways in which spirituality functions as an internal resource for resiliency at the biological level, and how this can be supported through effective, culturally tailored interventions. Social support and a sense of community are equally powerful[60,61]. Efforts to prioritize measures for empirical evaluation should consider both negative exposures and positive mediating influences.

\section{Conclusion}

Emerging epigenetics research has demonstrated associations between methylation of HPA-related genes and increased risk of numerous diseases. This research has also demonstrated associations of diverse maternal psychosocial stressors and infant DNA methylation of HPA axis-related genes, as well as associations between such methylation in infants and diverse fetal outcomes. Maternal exposures affecting infant DNA modifications are not limited to exposures the mother experiences during pregnancy, but extend to adverse experiences the mother had during her own childhood. Epigenetics research thus emphasizes the inextricable link between a woman's health throughout her lifecourse, and her child's health throughout his or her lifecourse. With respect to disparities, emerging epigenetics research suggests that supporting the material and psychosocial health of poor and minority women throughout the lifecourse should be a cornerstone of any long-term strategy to not only address perinatal and infant health, but to eliminate health disparities in the general population. We cannot have healthy mothers without having healthy and safe social and physical environments in which they can live, work, and exercise, and without safe and healthy food that they can access. In its most essential form, environmental epigenetics research emphasizes the central importance of public health and the insidious ways that social inequality sets up disadvantaged individuals to have poorer health from birth. Epigenetic research suggests that health promotion must not only begin from the prenatal period, but must take an intergenerational perspective, encompassing the potential for each child's mother to have a healthy life. This is a radical shift in perspective. While such a broad scope may seem overwhelming to public policy makers, emerging science suggests that such a comprehensive approach is necessary if we want to tackle health disparities at their root.

Emerging epigenetics and other research that is beginning to elucidate the biological mechanisms and pathways underlying disease etiology hold great potential to inform public health investment in order to maximally improve population health and reduce health disparities. Maximizing the potential of this exciting science to generate new knowledge will require a coordinated, strategic effort among national cohort leaders to empirically evaluate measures of key social and environmental exposures important for advancing the study of mechanisms underpinning disease etiology, and to prioritize measures for common data collection. Given the potential public health impact of this national effort, it should be a high priority for federal policy makers and receive robust technical and financial support. Public investment in understanding 
how psychosocial, social and environmental factors "get under the skin" to affect individuals' epigenome and downstream vulnerability to disease, and understanding which positive modifying influences are able to mitigate the impact of these adverse influences to promote resiliency and health, are likely to produce an enormous population health benefit. Realizing this potential to meaningfully identify new leverage points for reducing disease risk and improving population health - through more precisely understanding the mechanisms and biological pathways through which disadvantage and adversity influence health -

\section{References}

1 Wilkinson I, Kleinman A. A Passion for Society: How We Think About Human Suffering. University of California Press, CA., USA (2016).

2 Barker D, Barker M, Fleming T, Lampl M. Developmental biology: support mothers to secure future public health. Nature 504(7479), 209-211 (2013).

3 Barker DJ. The fetal and infant origins of adult disease. BMJ 301(6761), 1111 (1990).

4 Conradt E, Lester BM, Appleton AA, Armstrong DA, Marsit CJ. The roles of DNA methylation of NR3C1 and 11betaHSD2 and exposure to maternal mood disorder in utero on newborn neurobehavior. Epigenetics 8(12), 1321-1329 (2013).

5 Drake AJ, Mcpherson RC, Godfrey KM et al. An unbalanced maternal diet in pregnancy associates with offspring epigenetic changes in genes controlling glucocorticoid action and foetal growth. Clin. Endocrinol. 77(6), 808-815 (2012).

6 Mulligan CJ, D'errico NC, Stees J, Hughes DA. Methylation changes at $\mathrm{NR} 3 \mathrm{C} 1$ in newborns associate with maternal prenatal stress exposure and newborn birth weight. Epigenetics 7(8), 853-857 (2012).

7 Oberlander TF, Weinberg J, Papsdorf M, Grunau R, Misri $S$, Devlin AM. Prenatal exposure to maternal depression, neonatal methylation of human glucocorticoid receptor gene (NR3C1) and infant cortisol stress responses. Epigenetics 3(2), 97-106 (2008).

8 Entringer S, Buss C, Wadhwa PD. Prenatal stress, development, health and disease risk: a psychobiological perspective-2015 Curt Richter Award Paper. Psychoneuroendocrinol. 62, 366-375 (2015).

9 Nagarajan S, Seddighzadeh B, Baccarelli A, Wise LA, Williams M, Shields AE. Adverse maternal exposures, methylation of glucocorticoid-related genes and perinatal outcomes: a systematic review. Epigenomics 8(7), 925-944 (2016).

10 Hompes T, Izzi B, Gellens E et al. Investigating the influence of maternal cortisol and emotional state during pregnancy on the DNA methylation status of the glucocorticoid receptor gene (NR3C1) promoter region in cord blood. J. Psychiatr. Res. 47(7), 880-891 (2013). should be an urgent national priority. Lives of future generations may literally be at stake.

\section{Financial \& competing interests disclosure}

This work was financially supported by The John Templeton Foundation (grant \#48424). The author has no other relevant affiliations or financial involvement with any organization or entity with a financial interest in or financial conflict with the subject matter or materials discussed in the manuscript apart from those disclosed.

No writing assistance was utilized in the production of this manuscript.

11 Appleton AA, Armstrong DA, Lesseur C et al. Patterning in placental 11-B hydroxysteroid dehydrogenase methylation according to prenatal socioeconomic adversity. PLoS ONE 8(9), e74691 (2013).

12 Sternthal MJ, Enlow MB, Cohen S et al. Maternal interpersonal trauma and cord blood IgE levels in an inner-city cohort: a life-course perspective. J. Allergy Clin. Immunol. 124(5), 954-960 (2009).

13 Sternthal MJ, Coull BA, Chiu YH, Cohen S, Wright RJ. Associations among maternal childhood socioeconomic status, cord blood IgE levels, and repeated wheeze in urban children. J. Allergy Clin. Immunol. 128(2), 337.e331-345. e331 (2011).

14 Cheng ER, Park H, Wisk LE et al. Examining the link between women's exposure to stressful life events prior to conception and infant and toddler health: the role of birth weight. J Epidemiol. Community Health 70 (3), 245-252 (2016).

15 Bowers ME, Yehuda R. Intergenerational transmission of stress in humans. Neuropsychopharmacol. 41(1), 232-244 (2016).

16 Yehuda R, Daskalakis NP, Bierer LM et al. Holocaust exposure induced intergenerational effects on FKBP5 methylation. Biol. Psychiatry 80(5), 372-380 (2015).

17 Sen A, Heredia N, Senut MC et al. Multigenerational epigenetic inheritance in humans: DNA methylation changes associated with maternal exposure to lead can be transmitted to the grandchildren. Sci. Rep. 5, 14466 (2015).

18 Tang WW, Dietmann S, Irie N et al. A unique gene regulatory network resets the human germline epigenome for development. Cell 161(6), 1453-1467 (2015).

19 Argentieri MA, Nagarajan S, Seddighzadeh B, Baccarelli AA, Shields AE. Epigenetic pathways in human disease: the impact of DNA methylation on stress-related pathogenesis and current challenges in biomarker development. EBioMedicine (2017) (In Press).

20 Lien HC, Lu YS, Cheng AL et al. Differential expression of glucocorticoid receptor in human breast tissues and related neoplasms. J. Pathol. 209(3), 317-327 (2006).

21 Kay P, Schlossmacher G, Matthews L et al. Loss of glucocorticoid receptor expression by DNA methylation prevents glucocorticoid induced apoptosis in human small cell lung cancer cells. PLoS ONE 6(10), e24839 (2011). 
22 Dammann G, Teschler S, Haag T, Altmuller F, Tuczek F, Dammann RH. Increased DNA methylation of neuropsychiatric genes occurs in borderline personality disorder. Epigenetics 6(12), 1454-1462 (2011).

$23 \mathrm{Na}$ KS, Chang HS, Won E et al. Association between glucocorticoid receptor methylation and hippocampal subfields in major depressive disorder. PLoS ONE 9(1), e85425 (2014)

24 Melas PA, Wei Y, Wong CC et al. Genetic and epigenetic associations of MAOA and NR3C1 with depression and childhood adversities. Int. J. Neuropsychopharmacol. 16(7), 1513-1528 (2013).

25 Veenendaal MV, Costello PM, Lillycrop KA et al. Prenatal famine exposure, health in later life and promoter methylation of four candidate genes. J. Dev. Orig. Health Dis. 3(6), 450-457 (2012).

26 Blair LJ, Nordhues BA, Hill SE et al. Accelerated neurodegeneration through chaperone-mediated oligomerization of tau. J. Clin. Invest. 123(10), 4158-4169 (2013).

27 Yehuda R, Daskalakis NP, Desarnaud F et al. Epigenetic biomarkers as predictors and correlates of symptom improvement following psychotherapy in combat veterans with PTSD. Front. Psychiatry 4, 118 (2013).

28 Labonte B, Azoulay N, Yerko V, Turecki G, Brunet A. Epigenetic modulation of glucocorticoid receptors in posttraumatic stress disorder. Transl. Psychiatry 4, e368 (2014).

29 Yehuda R, Flory JD, Bierer LM et al. Lower methylation of glucocorticoid receptor gene promoter 1 in peripheral blood of veterans with posttraumatic stress disorder. Biol. Psychiatry 77(4), 356-364 (2015).

30 Vukojevic V, Kolassa IT, Fastenrath M et al. Epigenetic modification of the glucocorticoid receptor gene is linked to traumatic memory and post-traumatic stress disorder risk in genocide survivors. J. Neurosci. 34(31), 10274-10284 (2014).

31 Klengel T, Mehta D, Anacker C et al. Allele-specific FKBP5 DNA demethylation mediates gene-childhood trauma interactions. Nat. Neurosci. 16(1), 33-41 (2013).

32 Smyth LJ, Mckay GJ, Maxwell AP, Mcknight AJ. DNA hypermethylation and DNA hypomethylation is present at different loci in chronic kidney disease. Epigenetics 9(3), 366-376 (2014).

33 Friso S, Pizzolo F, Choi SW et al. Epigenetic control of 11 beta-hydroxysteroid dehydrogenase 2 gene promoter is related to human hypertension. Atherosclerosis 199(2), 323-327 (2008).

34 Pratt GC, Vadali ML, Kvale DL, Ellickson KM. Traffic, air pollution, minority and socio-economic status: addressing inequities in exposure and risk. Int. J. Environ. Res. Public Health 12(5), 5355-5372 (2015).

35 Bell ML, Ebisu K. Environmental inequality in exposures to airborne particulate matter components in the United States. Environ. Health Perspect. 120(12), 1699-1704 (2012).

36 Lin VW, Baccarelli AA, Burris HH. Epigenetics-a potential mediator between air pollution and preterm birth. Environ. Epigenet. 2(1), doi:10.1093/eep/dvv008 (2016).
37 Burris HH, Baccarelli AA, Wright RO, Wright RJ Epigenetics: linking social and environmental exposures to preterm birth. Pediatr. Res. 79(1-2), 136-140 (2016).

38 Lock M. Comprehending the body in the era of the epigenome. Curr. Anthropol. 56(2), 151-177 (2015).

39 Niewöhner J. Epigenetics: embedded bodies and the molecularisation of biography and milieu. BioSocieties 6(3), 279-298 (2011).

40 U.S. Department of Health and Human Services. HHS action plan to reduce racial and ethnic health disparities (2011). www.minorityhealth.hhs.gov

41 Powers M, Faden R. Social Justice: The Moral Foundations of Public Health and Health Policy. Oxford University Press, UK (2006).

42 Pargament KI, Koenig HG, Perez LM. The many methods of religious coping: development and initial validation of the RCOPE. J. Clin. Psychol. 56(4), 519-543 (2000).

43 Pew Research Center. Religious landscape study. Pew forum on religion and public life (2014). www.pewforum.org/religious-landscape-study/

44 Trevino KM, Pargament KI, Cotton S et al. Religious coping and physiological, psychological, social, and spiritual outcomes in patients with HIV/AIDS: crosssectional and longitudinal findings. AIDS Behav. 14(2), 379-389 (2010).

45 Ironson G, Stuetzle R, Fletcher MA. An increase in religiousness/spirituality occurs after HIV diagnosis and predicts slower disease progression over 4 years in people with HIV. J. Gen. Intern. Med. 21(S5), S62-S68 (2006)

46 Kremer H, Ironson G, Kaplan L, Stuetzele R, Baker N, Fletcher MA. Spiritual coping predicts CD4-cell preservation and undetectable viral load over four years. AIDS Care 27(1), 71-79 (2015).

47 Reynolds N, Mrug S, Britton L, Guion K, Wolfe K, Gutierrez H. Spiritual coping predicts 5-year health outcomes in adolescents with cystic fibrosis. J. Cystic Fibrosis 13(5), 593-600 (2014).

48 Trevino KM, Mcconnell TR. Religiosity and religious coping in patients with cardiovascular disease: change over time and associations with illness adjustment. J. Relig. Health 53(6), 1907-1917 (2014).

49 Mohr S, Perroud N, Gillieron C et al. Spirituality and religiousness as predictive factors of outcome in schizophrenia and schizo-affective disorders. Psychiatry Res. 186(2-3), 177-182 (2011).

50 Oxman TE, Freeman DH Jr, Manheimer ED. Lack of social participation or religious strength and comfort as risk factors for death after cardiac surgery in the elderly. Psychosom. Med. 57(1), 5-15 (1995).

51 Bonaguidi F, Michelassi C, Filipponi F, Rovai D. Religiosity associated with prolonged survival in liver transplant recipients. Liver Transplant. 16(10), 1158-1163 (2010).

52 Morgan N, Irwin MR, Chung M, Wang C. The effects of mind-body therapies on the immune system: meta-analysis. PLoS ONE 9(7), e100903 (2014). 
53 Greenlee H, Balneaves LG, Carlson LE et al. Clinical practice guidelines on the use of integrative therapies as supportive care in patients treated for breast cancer. J. Natl. Cancer Inst. Monogr. 2014(50), 346-358 (2014).

54 Bower JE, Crosswell AD, Stanton AL et al. Mindfulness meditation for younger breast cancer survivors: a randomized controlled trial. Cancer 121(8), 1231-1240 (2015).

55 Carlson LE, Doll R, Stephen J et al. Randomized controlled trial of mindfulness-based cancer recovery versus supportive expressive group therapy for distressed survivors of breast cancer. J. Clin. Oncol. 31(25), 3119-3126 (2013).

56 Oh B, Butow PN, Mullan BA et al. Effect of medical Qigong on cognitive function, quality of life, and a biomarker of inflammation in cancer patients: a randomized controlled trial. Support Care Cancer 20 (6), 1235-1242 (2012).

57 Brook RD, Appel LJ, Rubenfire $M$ et al. Beyond medications and diet: alternative approaches to lowering blood pressure: a scientific statement from the American Heart Association. Hypertension 61(6), 1360-1383 (2013).

58 Nidich SI, Rainforth MV, Haaga DA et al. A randomized controlled trial on effects of the transcendental meditation program on blood pressure, psychological distress, and coping in young adults. Am. J. Hypertens. 22 (12), 1326-1331 (2009).

59 Goyal M, Singh S, Sibinga EM et al. Meditation programs for psychological stress and well-being: a systematic review and meta-analysis. JAMA Intern. Med. 174(3), 357-368 (2014).

60 McEwen B. Physiology and neurobiology of stress and adaptation: central role of the brain. Physiol. Rev. 87(3), 873-904 (2006).

61 Berkman L, Glass T, Brissette I, Seemandet TE. From social integration to health: Durkheim in the new millennium. Soc. Sci. Med.51(6), 843-857 (2000). 